\title{
Tremor Assessment - On Disability Scale and Functional Performance Test
}

Man Mohan Mehndiratta1*, Munish Kumar² and Sanjay Pandey ${ }^{3}$

${ }^{1}$ Department of Neurology, Janakpuri Superspeciality Hospital, India

${ }^{2}$ Department of Neurology, G.B Pant Hospital, India

${ }^{3}$ Department of Neurology, Chief, Parkinson disease and Movement disorder clinic, G.B Pant Hospital, India

\begin{abstract}
Tremor is the most common movement disorder. The objective of the current study was to find correlation between disability due to tremor (daily living score) with the functional performance tests like nine-hole peg and box and block. A total of 100 subjects with tremor, categorized in seven diagnostic groups fulfilling the respective diagnostic criteria studied. Clinical assessment using activities of daily living scales (ADL-T24) and tremor severity score done on each patient. The nine-hole peg score (in seconds) and box and block score (number of blocks in 60 seconds) calculated in each. We found that tremor severity was proportionate to ADL-T24 score and had a positive correlation with the disease duration. Overall, there was a moderate positive correlation between ADL-T24 score and 9-HPT score $\left(R^{2}=0.52\right)$ whereas a strong negative correlation between ADL-T24 and BBT score $\left(R^{2}=-0.66\right)$. An inverse pattern was observed between 9-HPT score and BBT score with a moderate negative correlation $\left(R^{2}=-0.58\right)$. It was concluded that the functional performance tests correlate well with the daily living scores. Thus the tremor severity can be quantified on time based measures and are useful for tremor assessment.
\end{abstract}

Keywords: Tremor; Disability scale; Functional performance test

\section{Introduction}

Tremor defined as "a rhythmic, involuntary oscillatory movement of a body part." It is repetitive and stereotyped that distinguishes it from other involuntary movements like chorea, athetosis, ballism, tics, and myoclonus [1]. Tremor impacts the performance of fine motor skills such as feeding, dressing, drinking, writing, body care, and fine object manipulation thereby leading to social embracement $[2,3]$. Measures of health related quality of life are increasingly used as outcome indicators in patients with neurological disorders [4]. The severity of tremor can be measured with a variety of clinical eg rating scales, quality-of-life questionnaires, spirography (Archimedes' spirals) and functional performance tests eg nine-hole peg test (9HPT) and box and block test (BBT). Various rating scales were designed specifically for the assessment of tremor, impact on activities of daily living (ADL) and quality of life [5]. Effect of tremor on daily living activities can be evaluated using specific questionnaires such as the ADL-T24, which has a good inter-session reproducibility [6]. The 9-HPT and BBT are simple, low-cost, and efficient test of gross manual dexterity with a high inter-rater reliability ( $\mathrm{r}=0.96, \mathrm{r}=0.99$ respectively) and good testretest reliability $(r=0.69, r=0.94$ respectively) $[7,8]$. The purpose of this study is to correlate disability due to tremor (daily living score) with the functional performance test.

\section{Design/Methods}

A total of 100 patients, more than 12 years of age, having different kind of tremors that presented to a tertiary care hospital in New Delhi, India between April 2012 to September 2013 were prospectively analyzed for clinical details and functional performance tests. This study was carried after ethical clearance and permission of the institute. A written informed consent was taken from subjects (parents in case of a minor), after adequate explanation.

All patients were subjected to general physical and detailed neurological examination. Clinically, patients were divided into seven diagnostic groups fulfilling the respective diagnostic criteria; Parkinson's disease (PD) [9] $(n=45)$, Essential tremor (ET) [10] $(\mathrm{n}=33)$, Psychogenic tremor [11] $(\mathrm{n}=07)$, Valproate induced tremor $(n=07$, those patients in which the tremor developed after the initiation of sodium valproate monotherapy), Cerebellar tremor [10] $(\mathrm{n}=03)$, Primary writing tremor [10] $(n=03)$ and Rubral tremor[10] $(n=02)$. Assessment of disability was done using ADL-T24 scale (Activities of Daily Living scales) [6]. Tremor severity in most affected upper extremity was assessed on the basis of difficulties encountered while doing activities of daily living [12]. Tremor severity were divided into mild, moderate, severe, and incapacitating - Mild (1) - able to do the activity without difficulty, Moderate (2) - able to do the activity with a little effort, Severe (3) - able to do the activity with a lot of effort and Incapacitating (4) - cannot do the activity by himself [12]. A particular tremor rating scale was not chosen as there were different diagnostic groups. So to make uniformity among different types of tremor groups a daily living scale (ADL-T24) used. The functional performance tests performed were - 1.) 9-HPT [7] - The time taken (measured in seconds) during placing and removing nine pegs in a pegboard and 2.) BBT [8] It consists of moving, one by one, the maximum number of blocks $(2.5$ $\mathrm{cm}^{3}$ ) from one compartment of a box to another of equal size within 60 seconds. These tests were used because they had good test-retest and inter-rater reliability. Demographic data, ADL-T24 score, and functional performance test scores were recorded and analyzed using SPSS v20. 0 software. Values were expressed as mean \pm SD or mean \pm SE. The Pearson's correlation coefficient $(r)$ calculated and considered as poor if $r<0.3$ and moderate if $0.3<r<0.5$ and strong if $r>0.5$.

\section{Results}

One hundred patients with different types of tremor were clinically evaluated and classified as PD $(n=45)$ and ET $(n=33)$, psychogenic

*Corresponding author: Man Mohan Mehndiratta, Director, Professor and Head Department of Neurology, Janakpuri Superspeciality Hospital, Janakpuri, New Delhi-110058, India, Tel: 0091-112552023; Fax: 0091-112552024; E-mail: mmehndi@hotmail.com

Received April 28, 2015; Accepted July 27, 2015; Published July 29, 2015

Citation: Mehndiratta MM, Kumar M, Pandey S (2015) Tremor Assessment - On Disability Scale and Functional Performance Test. J Mol Biomark Diagn 5: 242 doi:10.4172/2155-9929.1000242

Copyright: (c) 2015 Mehndiratta MM, et al. This is an open-access article distributed under the terms of the Creative Commons Attribution License, which permits unrestricted use, distribution, and reproduction in any medium, provided the original author and source are credited 
$(\mathrm{n}=07)$, valproate induced $(\mathrm{n}=07)$, cerebellar $(\mathrm{n}=03)$, primary writing $(\mathrm{n}=03)$ and rubral $(\mathrm{n}=02)$ tremor. Sixty nine patients were males and 31 females (M: F ratio=2. 22:1). Their mean $\pm \mathrm{SD}$ age was $48.91 \pm 18.2$ years (range 13-91 years) (Table 1).

Forty-five patients had PD tremor, the mean \pm SD age was $54.48 \pm$ 13.39 years (range 13-75 years) with male: female ratio was 1.65:1 and mean disease duration was 3.45 years. The rest and postural tremor both were present in $91.11 \%$ patients and either type of tremor in $4.44 \%$ each.

Thirty-three patients had ET, the mean \pm SD age was $51.51 \pm$ 19.04 years (range 15 to 91 years) with male: female ratio was 10:1 i.e. males more common than females and out of which five (15.15\%) had positive family history. Their mean disease duration was 3.93 years. Phenomenologically tremor was mainly action/postural in $90.9 \%$, remaining had a rest and intention type also.

Among other diagnostic groups, seven patients with psychogenic tremor having symptom duration 6 months to 6 years (mean 20 months) and obvious stressors, four males and three females with mean \pm SD age $37.28 \pm 17.71$ years. The tremor was present in all limb positions. Seven patients (two males and five females) with epilepsy on monotherapy with valproate (duration of treatment was 6 months to 2 years, mean duration of treatment was 0.93 years, mean \pm SD dose of valproate was $1500 \pm 500 \mathrm{mg}$ daily) developed tremor and all had action / postural tremor only. The mean \pm SD age was $24.28 \pm 7.45$ years. Three patients had cerebellar tremor with mean \pm SD age $31.0 \pm 16.7$ years, the tremor was present in all limb positions except at rest. Three male patients had a primary writing tremor involving dominant hand at the time of writing with mean \pm SD age $60.33 \pm 14.01$ years and mean disease duration was 3.17 years. Two of rubral tremor, both post-operated cases of hypothalamic hamartoma with a mean \pm SD age $17.0 \pm 5.65$ years and tremor was present in all limb positions.

Among all patients, $42 \%$ had mild tremor severity, $37 \%$ moderate, $9 \%$ severe and $2 \%$ incapacitating type. The mean ADL-T24 score was 3.40 in mild, 8.46 in moderate, 14.89 in severe and 23.0 in incapacitating type of tremor (Figure 1). The mean ADL-T24 score was highest for rubral tremor $(23.0 \pm 2.82)$ and lowest for primary writing tremor $(3.66$ $\pm 2.08)$. The mean ADL-T24 score for ET $(4.42 \pm 4.72)$ and valproate induced tremor $(3.71 \pm 2.91)$ was almost the same whereas for PD tremor $(8.04 \pm 5.99)$, it was higher.
The mean disease duration had positive correlation with the ADL-T24 score in different types of tremor except primary writing and psychogenic tremor in which there was a negative correlation (Figure 1).

The time taken during 9-HPT was highest for rubral (121.36 \pm 14.26 seconds) and lowest for ET (16.06 \pm 4.52 seconds) whereas reverse pattern was seen with the BBT score (Table 1).

Overall a positive correlation between ADL-T24 score and 9-HPT $\left(\mathrm{R}^{2=} 0.52\right)$ but a negative correlation between ADL-T24 and BBT score $\left(\mathrm{R}^{2}-0.66\right)$ (Figure 2). Same pattern seen in each diagnostic group. A negative correlation was seen between 9-HPT score and BBT score. The correlation coefficient between them was -0.58 .

\section{Discussion}

The ADL-T24 score was proportionate to tremor severity. The mild to moderate tremor was more common than severe and incapacitating type. All of the tremor diagnostic groups had mild to moderate tremor severity except rubral that had severe type of tremor. The PD tremor had higher mean ADL-T24 score as compared to ET $(8.04 \pm 5.99,4.42$ \pm 4.72 respectively), this could be due to other confounding factors like bradykinesia or rigidity in PD. Clinically the ET resembles valproate induced tremor as both having predominant postural tremor and their mean ADL-T24 scores were also almost the same (4.42 \pm 4.72 , $3.71 \pm 2.91$ respectively). A study by Karas et al. also found the clinical resemblance between ET and valproate induced tremor [13]. The mean ADL-T24 score was highest for rubral tremor $(23.0 \pm 2.82)$ and lowest for primary writing tremor $(3.66 \pm 2.08)$. This shows that rubral tremor had severe type of tremor and had much difficulty in doing daily living activities. There was a positive correlation between the disease duration and mean ADL-T24 score except psychogenic and primary writing tremor. This shows that as the disease progress, the daily living activities become more difficult. In psychogenic tremor there are inconsistency and variability of symptoms, thus the tremor severity does not correlate well with a daily living score. The primary writing tremor is a task specific tremor that may not affect other functions of daily living except writing even if the disease is progressing, hence the tremor severity may not parallel with overall ADL-T24 score.

We found a Mean \pm SD score of $28.20 \pm 6.80$ seconds in PD tremor on the hole peg test. Associated rigidity and bradykinesia could be contributory for the greater time score. Almost similar results were found by Earhart et al. [14] $31.4 \pm 15.7$ seconds and Ellis et al. [15]

\begin{tabular}{|c|c|c|c|c|c|c|c|c|c|c|c|}
\hline \multirow[b]{2}{*}{ Diagnosis } & \multicolumn{2}{|l|}{ Sex } & \multirow[b]{2}{*}{ Total } & \multirow[b]{2}{*}{$\begin{array}{l}\text { Age } \\
\text { Mean } \pm \text { SD } \\
\text { (years) }\end{array}$} & \multirow[b]{2}{*}{$\begin{array}{l}\text { Symptom } \\
\text { duration in } \\
\text { years (Mean) }\end{array}$} & \multirow[b]{2}{*}{$\begin{array}{l}\text { Tremor } \\
\text { phenomenology }\end{array}$} & \multirow[b]{2}{*}{$\begin{array}{l}\text { ADL- T } 24 \\
\text { Mean } \pm \text { SD }\end{array}$} & \multirow{2}{*}{$\begin{array}{l}9 \text { Hole-peg } \\
\text { score in } \\
\text { seconds } \\
\text { (Mean } \pm \text { SD) }\end{array}$} & \multirow{2}{*}{$\begin{array}{l}\text { Box and block } \\
\text { score (number } \\
\text { of blocks) } \\
\text { (Mean } \pm \text { SD) }\end{array}$} & \multicolumn{2}{|c|}{ Correlation coefficients } \\
\hline & Female & Male & & & & & & & & $\begin{array}{l}\text { ADL - T24 } \\
\text { vs. 9-Hole } \\
\text { peg test }\end{array}$ & $\begin{array}{l}\text { ADL - T24 } \\
\text { vs. Box and } \\
\text { block test }\end{array}$ \\
\hline $\begin{array}{l}\text { Parkinsonian } \\
\text { tremor }\end{array}$ & 17 & 28 & 45 & $54.48 \pm 13.39$ & 3.45 & R P & $8.04 \pm 5.99$ & $28.20 \pm 6.80$ & $29.54 \pm 8.70$ & 0.49 & -0.7 \\
\hline Essential Tremor & 3 & 30 & 33 & $51.51 \pm 19.04$ & 3.93 & PKI & $4.42 \pm 4.72$ & $16.06 \pm 4.52$ & $45.31 \pm 8.94$ & 0.78 & -0.83 \\
\hline $\begin{array}{l}\text { Psychogenic } \\
\text { tremor }\end{array}$ & 3 & 4 & 7 & $37.28 \pm 17.71$ & 1.67 & R P & $8.71 \pm 6.64$ & $16.83 \pm 3.99$ & $40.14 \pm 5.82$ & 0.59 & -0.69 \\
\hline $\begin{array}{l}\text { Valproate induced } \\
\text { tremor }\end{array}$ & 5 & 2 & 7 & $24.28 \pm 7.45$ & 0.93 & $\mathrm{P}$ & $3.71 \pm 2.91$ & $19.64 \pm 8.33$ & $40.57 \pm 10.52$ & 0.46 & -0.52 \\
\hline Cerebellar tremor & 2 & 1 & 3 & $31.0 \pm 16.7$ & 3.00 & $\mathrm{PKI}$ & $6.0 \pm 1.63$ & $18.13 \pm 3.64$ & $43.66 \pm 9.07$ & 0.42 & -0.81 \\
\hline $\begin{array}{l}\text { Primary writing } \\
\text { tremor }\end{array}$ & 0 & 3 & 3 & $60.33 \pm 14.01$ & 3.17 & $\mathrm{~T}$ & $3.66 \pm 2.08$ & $25.20 \pm 5.87$ & $28.00 \pm 4.93$ & 0.29 & -0.47 \\
\hline Rubral tremor & 1 & 1 & 2 & $17.0 \pm 5.65$ & 1.00 & R P K I & $23.0 \pm 2.82$ & $121.3 \pm 14.26$ & $9.25 \pm 4.64$ & - & - \\
\hline Total & 31 & 69 & 100 & & & & & & & & \\
\hline
\end{tabular}

R: Rest, P: Postural, K: Kinetic, I: Intention, T: Task- specific, ADL-T24: Questionnaire of tremor-induced difficulties encountered during daily life 
Citation: Mehndiratta MM, Kumar M, Pandey S (2015) Tremor Assessment - On Disability Scale and Functional Performance Test. J Mol Biomark Diagn 5: 242. doi:10.4172/2155-9929.1000242

Correlation coefficient - Disease duration Vs ADL-T24

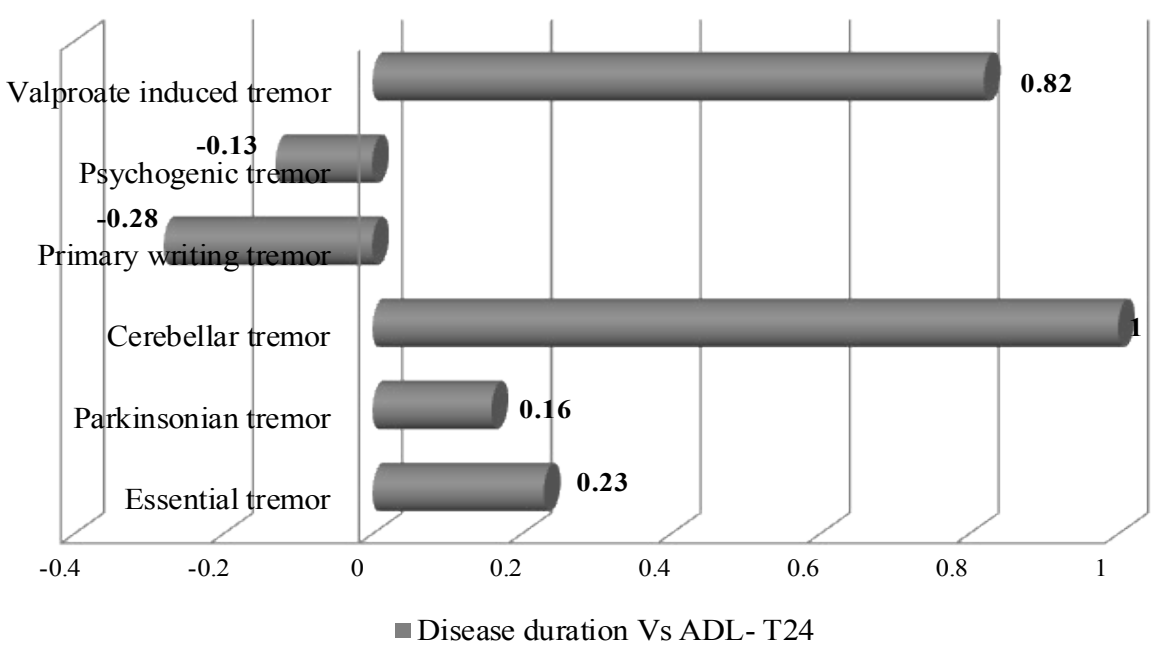

Figure 1: Correlation between mean disease duration and ADL-T24 score.

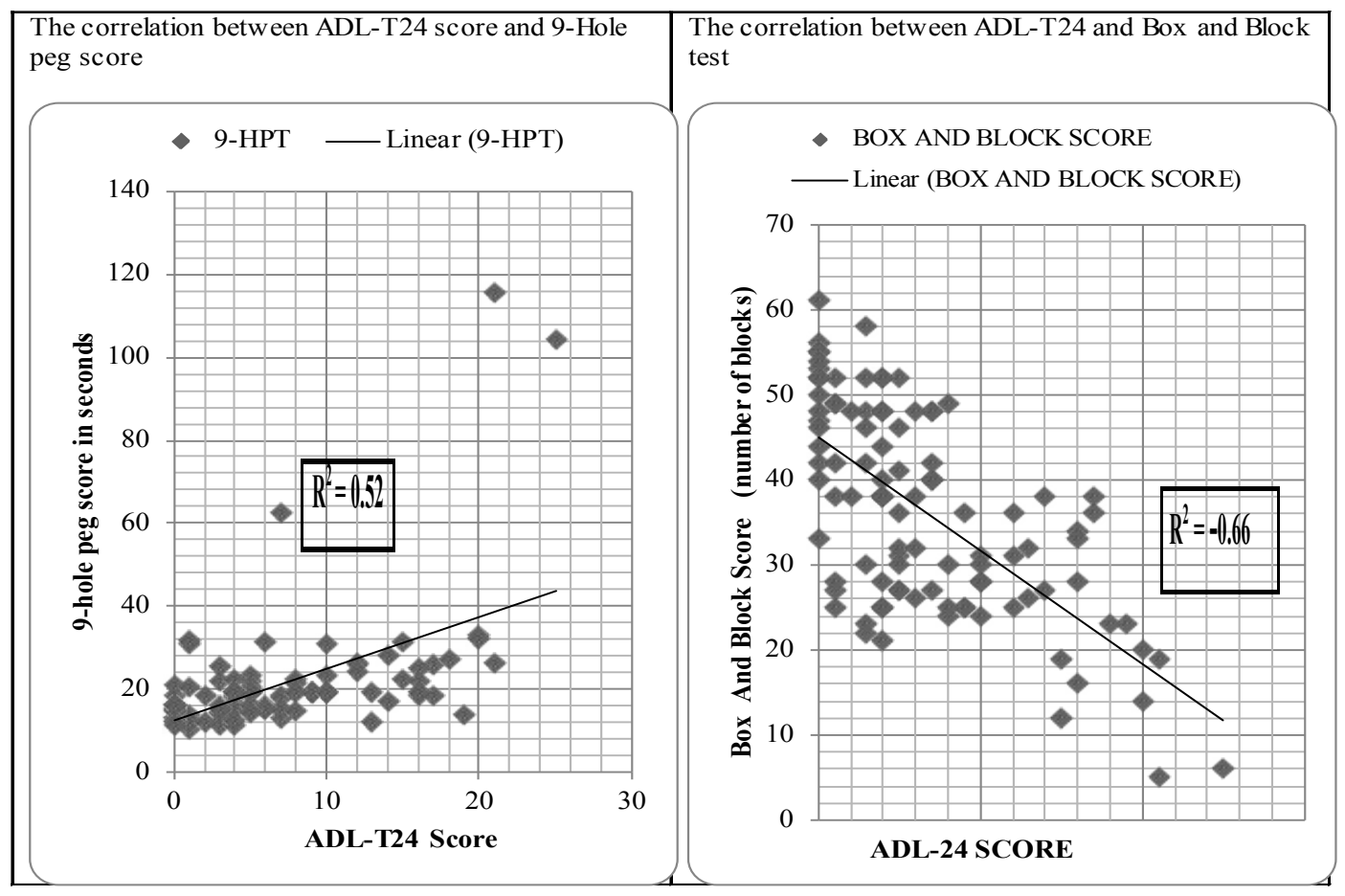

Figure 2: Correlation between ADL-T24 score and 9-Hole peg test score, Box and Block test score.

$32.2 \pm 12.4$ seconds. Bradykinesia and freezing of gait scores predicted significant portions of the variance in 9-HPT time in patients with PD, even then this test appears to be a clinically useful measure for assessing upper extremity function with good test-retest reliability ( $\mathrm{r}=0.88)$ [14]. The 9-HPT score was lowest for ET (16.06 \pm 4.52 seconds) whereas highest for rubral tremor $(121.36 \pm 14.26$ seconds $)$ and vice-versa for the BBT score, which was highest for ET $(45.31 \pm 8.94)$ and lowest for rubral tremor $(9.25 \pm 4.64)$. A study by Héroux et al. found that ET patients had measurable disability on time-based measures of upperextremity function (9HPT, BBT) [16]. Various studies showed that the pegboard test can be used for treatment assessment in patients with ET. In these patients, a short-term resistance-training program of the upper limb can improve fine manual dexterity as determined by a significant increase in the pegboard test score $[17,18]$. Cerebellar tremor had a score of $18.13 \pm 3.64$ seconds on hole peg test. The pegboard test can accurately reflect the severity of the cerebellar function [19]. 
Citation: Mehndiratta MM, Kumar M, Pandey S (2015) Tremor Assessment - On Disability Scale and Functional Performance Test. J Mol Biomark Diagn 5: 242. doi:10.4172/2155-9929.1000242

Page 4 of 4

Overall, there was a moderate positive correlation between ADL-T24 score and 9-HPT score $\left(\mathrm{R}^{2} 0.52\right)$ whereas a strong negative correlation between ADL-T24 and BBT score $\left(\mathrm{R}^{2}=-0.66\right)$ (Figure 2). This signifies that those having higher ADL-T24 scores will take longer time to complete 9-HPT and lesser number of blocks be transferred in one minute. Similar results of positive and negative correlation were found in each diagnostic group separately. A study by Girimaldi G also found a positive correlation between ADL-T24 score and 9-HPT score $\left(\mathrm{R}^{2}=0.89\right)$ and a negative correlation between ADL-T24 and BBT score $\left(\mathrm{R}^{2}=-0.66\right)$ [20]. Reciprocal pattern was seen between 9-HPT score and BBT score with a moderate negative correlation $\left(\mathrm{R}^{2}=-0.58\right)$, similar to study by Girimaldi $\mathrm{G}\left(\mathrm{R}^{2}=-0.75\right)$ [20]. The comparative study of ADL-T24, 9-HPT score and BBT score with different types of tremor had not been reported previously. Thus the tremor severity correlates well with the functional performance tests. The limitation of our study was that there were less number of patients in other diagnostic groups except ET and PD tremor. The correlation coefficients between ADL-T24 score and 9-HPT score, BBT score of rubral tremor could not be calculated.

\section{Conclusion}

The severity of tremor can be measured with the help of quality-oflife questionnaires as well as with functional performance tests, e.g. the 9-HPT and BBT. The functional performance tests correlate well with the tremor severity and can be used to quantify it.

\section{References}

1. Bhidayasiri R (2001) Differential diagnosis of common tremor syndromes. Postgrad Med J 81: 756-762.

2. Louis ED, Barnes L, Albert SM, Cote L, Schneier FR, et al. (2001) Correlates of functional disability in essential tremor. Movement Disorders 16: 914-920.

3. Louis ED, Rios E (2009) Embarrassment in essential tremor: Prevalence clinical correlates and therapeutic implications. Parkinsonism Rel Disord 15: $535-538$.

4. Den Oudsten BL, Van Heck GL, De Vries J (2007) The suitability of patientbased measures in the field of Parkinson's disease: a systematic review. Movement Disorders 22: 1390-14401.

5. Elble R, Bain P, Forjaz MJ, Haubenberger D, Testa C, et al. (2013) Task force report: scales for screening and evaluating tremor: critique and recommendations. Movement Disorders 28: 1793-800.

6. Grimaldi G, Manto M (2010) Neurological Tremor: Sensors, Signal Processing and Emerging Applications Sensors 10: 1399-1422.

7. Mathiowetz V, Weber K, Kashman N, Volland G (1985) Nine Hole Peg Test: normative data for adults. Am J Occup Ther 5: 24-38.

8. Mathiowetz V, Volland G, Kashman N, Weber K (1985) Adult norms for the Box and Block Test of manual dexterity. Am J Occup Ther 39: 386-391.

9. Hughes AJ, Daniel SE, Kilford L, Lees AJ (1992) Accuracy of clinical diagnosis of idiopathic Parkinson's disease: a clinico-pathological study of 100 cases. Neurol Neurosurg Psychiatry 55: 181-184.

10. Deuschl G, Bain P, Brim M (1998) Consensus statement of the Movement Disorder Society on Tremor. Ad Hoc Scientific Committee. Movement Disorders 13: $2-23$.

11. Fahn S, Williams PJ (1988) Psychogenic dystonia. Adv Neurol 50: 431-455.

12. Bain PG, Findley FJ, Atchison P, Behari M, Vidailhet M et al.(1993) Assessing tremor severity. J Neurol Neurosurg Psychiatry 56: 868-873.

13. Karas BJ, Wilder BJ, Hammond EJ, Bauman AW (1982) Valproate tremors. Neurology 32: 428-432.

14. Earhart GM, Cavanaugh JT, Ellis T, Ford MP, Foreman KB, et al. (2011) The 9-hole PEG test of upper extremity function: average values, test-retest reliability, and factors contributing to performance in people with Parkinson disease. Journal of Neurologic Physical Therapy 35: 157-163

15. Ellis T, Cavanaugh JT, Earhart GM, Gord MP, Foreman KB, et al. (2011) Which Measures of Physical Function and Motor Impairment Best Predict Quality of Life in Parkinson's Disease?. Parkinsonism Relat Disord 17: 693-697.

16. Héroux ME, Parisi SL, Larocerie- Salgado J, Norman KE (2006) Upperextremity disability in essential tremor. Arch Phys Med Rehabil 87: 661-670.

17. Tolosa ES, Loewenson RB (1975) Essential tremor: treatment with propranolol. Neurology 25: 1041-1044.

18. Sequeira G, Keogh JW, Kavanagh JJ (2012) Resistance training can improve fine manual dexterity in essential tremor patients: a preliminary study. Arch Phys Med Rehabil 93: 1466-1468.

19. du Montcel ST, Charles P, Ribai P, Goizet C, Le Bayon A, et al. (2008) Composite cerebellar functional severity score: validation of a quantitative score of cerebellar impairment. Brain 131: 1352-1361.

20. Grimaldi G, Manto M (2013) Mechanisms and Emerging Therapies in Tremo Disorders. Contemporary Clinical Neuroscience 26: 325-340. 